\title{
Overcoming Difficulties in Understanding the Linear Equation System Through the Ethnomathematics Approach in the COVID-19 Pandemic
}

\author{
Dewi Herawaty $^{1}$, Wahyu Widada ${ }^{1, *}$, Abdurrobbil Falaq Dwi Anggoro ${ }^{1}$ and \\ Shadaqnas Dewarif Tri Anggoro ${ }^{2}$
}

\author{
${ }^{1}$ Mathematics Education Departement, Bengkulu University, Indonesia \\ ${ }^{2}$ SMA N 5 Bengkulu City, Indonesia \\ *Corresponding author. Email: w.widada@unib.ac.id
}

\begin{abstract}
The purposes of this study were to detect students' errors in understanding the two-variable system of linear equations during the Covid-19 Pandemic; and produce mathematics learning techniques to overcome student errors in understanding the system of two-variable linear equations through virtual learning during the Covid-19 Pandemic. Based on the formulation of the research problem, this type of research is exploratory research. This qualitative research is a procedure to reveal the nature of the symptoms that arise from the ethnomathematics of Bengkulu people. The main instrument in this research is the researcher himself and is guided by other instruments in the form of assignment sheets about mathematics problems based on local culture, as well as interview guidelines. In each stage of subject selection, the process of data collection was carried out directly through task-based interviews, and immediately followed by data analysis (namely genetic decomposition analysis). Based on the students 'genetic decomposition, alternatives were determined to correct students' difficulties regarding systems of linear equations. The results of this study are that the students' errors in concept, principal errors and operation errors. Students misrepresent the meaning of the system concept of variable linear equations. There are students who incorrectly apply the principles of elimination, substitution, and mixture to solve a system of linear variable equations. The technique of overcoming student errors during the COVID-19 pandemic is to apply an ethnomathematics approach that is taught through online learning (with the platform: learning management system and assisted by YouTube media). The conclusion of this research is that the students' mistakes in understanding the system of linear equations are misconceptions, principles and operations, which can be overcome through online ethno-mathematics approaches and YouTube media.
\end{abstract}

Keywords: Student error, System of equations, Ethnomathematics approach.

\section{INTRODUCTION}

We are currently facing the challenges posed by the COVID-19 pandemic and we must find solutions [1]. One of them is an effective practice for teaching and learning mathematics. It is a strategy that can provide useful clues to addressing challenges facing teachers, school leaders, and policy makers [2]. What's more, mathematics is a compulsory subject for students [3]. Also, the immediate objects of mathematics are abstract. This adds to the challenge for teachers and other mathematics educators in developing an appropriate lesson plan [4]. It requires a learning strategy that is in accordance with the students' initial abilities and the teaching materials available.

Solutions for students and teachers in implementing learning are an important concern. Currently schools are closed prematurely due to the still spreading corona virus. However, students can still engage in virtual math learning remotely using available digital platforms [1]. It is also one way to reduce the spread of COVID-19. Learning using google-classroom and telegram media assistance has been implemented. Google Classroom is an elearning system as a form of internet-based service provided by Google [5]. Therefore, the learning service does not stop but is now completely online. The pandemic would not affect students equally, however, would negatively affect the acquisition of cognitive and non-cognitive skills. Also, it has important long-term consequences in addition to short-term consequences [6]. In one study, it was shown that learning mathematics which is carried out through distance learning requires quality improvement from various aspects [7]. It is like preparation, facilities and infrastructure, material 
materials, and learning methods. Hence, some insight into what virtual classes look like is suggested. This can be done through optimizing online learning in mathematics learning. E-learning is learning by utilizing computers and internet technology to provide broad solutions. It is an attempt to ensure that learning takes place and improves performance [8].

The results showed that the subject's perceptions of the effectiveness of online learning and students' ability to attend e-learning sessions did not depend on lifestyle. Meanwhile, the results of the analysis of variance showed that the mathematical abilities they felt were significantly different [9]. Blended learning experiences have a positive effect on learning outcomes. Also, students' attitudes towards learning mathematics in a mixed environment. Boys and students with high abilities are more motivated in a blended learning environment. After experiencing mixed learning, students gave positive feedback about using an online learning platform for mathematics [10].

School mathematics is a formal deductive subject that is first encountered by students [11]. It was a difficult subject to deal with, such as understanding the concept of systems of linear equations, also quadratic equations [12]. In student learning requires a good cognitive process. Learning mathematics requires students to communicate actively, both oral and written communication [13]. Experience in the junior high school class, students have difficulty understanding the principle of solving systems of linear equations (SLE). Such as solving open problems that utilize the SLE mathematical model. However, students tend to solve it easily if the problem is close to their thoughts. Also problems based on local culture [14]. In the research of Widada et al. Stating that local culture has made it easier for students to recall the required concepts, making it easier for students to make interconnections between concepts. It has made it easier for students to achieve the principles of elimination, substitution, and mixture. The conclusion of this research is that ethnomathematics learning about Bengkulu fishermen culture can overcome students' difficulties in understanding the system of linear equations [14]. There is an improvement in the genetic decomposition of students in understanding the concepts and principles of mathematics through learning ethnomathematics. The increase is from lower to medium level [15]. Students can improve their abstraction skills during local culture-based learning [16][17]. Students have been able to analyze the relationship between concepts, axioms, and basic geometric properties through orange peel media (local culture). He has been able to associate and arrange the attributes obtained from the three segments that meet at the ends. Also, it has been able to arrange the triangular elements so that the multiangle property in the triangle is more than 180 [11]. These results indicate that local culture is a good approach to mathematics content for student learning. Based on this rationality, several research problems have been answered in this paper. That is how the description of students' errors in understanding the system of two-variable linear equations during the COVID-19 pandemic through virtual learning?; How to solve students' mistakes in understanding the system of two-variable linear equations during the COVID-19 pandemic through virtual learning?

\section{RESEARCH METHOD}

To answer the problem formulation, an exploratory research was conducted. It is a qualitative research, namely as a procedure to reveal the nature of the symptoms that arise from the ethnomathematics of Bengkulu people. The subjects of this study were twenty students. It was chosen purposively for students who had good initial abilities about the linear equation of one variable. This initial ability is a prerequisite for learning systems of linear equations. Students are taught through local culture-based learning. The main instrument in this research is the researcher himself and is guided by other instruments in the form of assignment sheets about mathematics problems based on local culture, as well as interview guidelines. Problem I is about buying "pempek ikan" and "kemplang" which are depicted in Figure 1. 


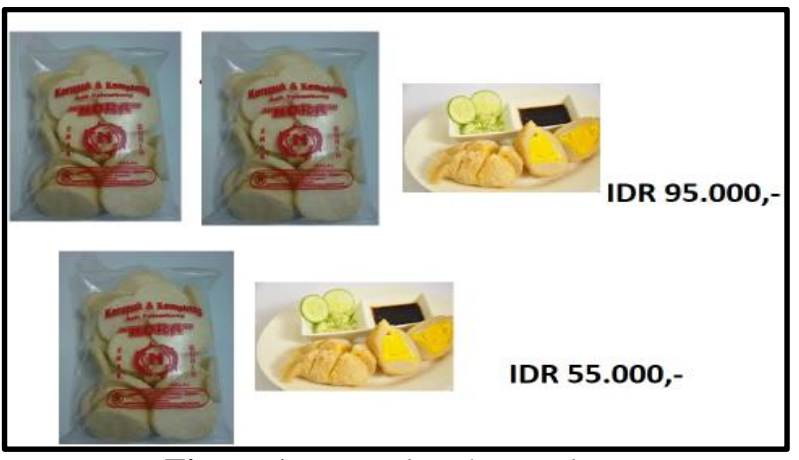

Figure 1. Pempek and Kemplang

Based on Figure 1, the subject is asked to complete the task, namely: what is the price of a bag of "kemplang"? Also specify a bag of "kemplang" and one "pekmpek" plate? Give your reasons.

Problem II is about the hat and tie used by the students during the Monday ceremony. Students are asked to collect hats and ties as shown in Figure 2.
The tasks that must be completed by students are: a. Without knowing the price for each hat and tie, can you determine which item is more expensive? Explain your reasons! b. How much is a hat? c. How much is a tie? d. How much for 2 hats and 5 ties?

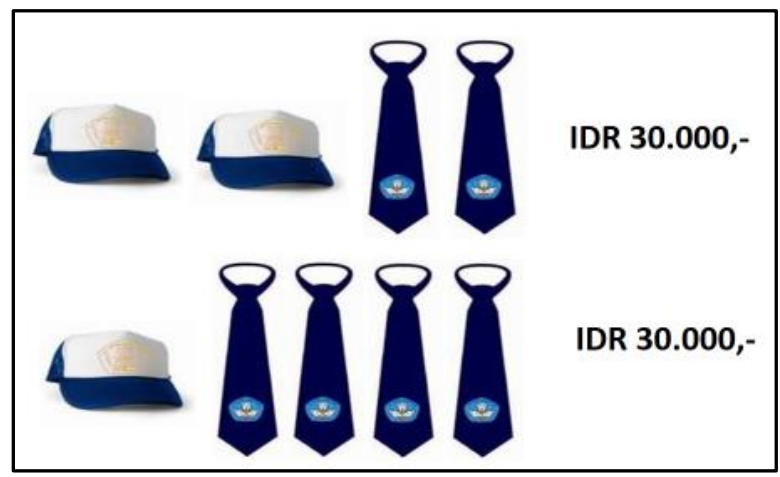

Figure 2. Hats and Ties

In each stage of subject selection, the process of data collection was carried out directly through task-based interviews, and immediately followed by data analysis (namely genetic decomposition analysis). Based on the students 'genetic decomposition, alternatives were determined to correct students' difficulties regarding systems of linear equations.

\section{RESULTS AND DISCUSSION}

At the time of the COVID-19 pandemic, we had carried out the mathematics learning process for junior high schools in Bengkulu-Indonesia through an LMS (learning management system). It has been implemented online and we have used a local cultural approach (ethnomatematics) as a material approach to mathematics. Also, have used the youtube media to provide assistance in understanding mathematical material. The media can be watched via the YouTube channel:

https://www.youtube.com/channel/UCiCwg0D_7fojd -_OiwfZh-g/videos. For the linear equation system material, students can watch this YouTube channel: https://www.youtube.com/watch?v=R-

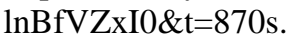

Based on task-based interviews with 20 selected junior high school students, we are interested in describing the two students who were interviewed in depth. The two students are Jn and Kt. Before using the YouTube media through this channel, students experienced several mistakes. The mistakes that students have made are misconceptions and principles. Consider the following interview excerpts. Snippet of R (researcher) interview with student (Jn):

$\mathrm{R}$ : What do you think the definition of a system of linear equations?

Jn:... Yes sir... it is a linear equation in a system....

R: What do you mean?

Jn: Linear equations that exist in any system ... I see Sir ...

$\mathrm{R}: \ldots$ how does it look?

Jn: Systems containing linear equations ... 
$\mathrm{R}$ : What is the system like?

Jn: ... the equation with the power of one Sir ...

$\mathrm{R}: \ldots$ for example $\mathrm{xy}+3 \mathrm{x}=2 \ldots$ is this a linear equation?

Jn: ... yes sir ... it's a linear equation, because $\mathrm{x}$ and $\mathrm{y}$ are to the power of $1 \ldots$

Based on the snippets of the interview with $\mathrm{Jn}$, it can be described that Jn had a misconception about linear equations. He said that $x y+3 x=2$ is a linear equation. Jn argues that $\mathrm{x}$ and $\mathrm{y}$ are to the 1 st power. That is the misconception of the linear equation that Jn experiences. The student also made a misconception about the system of linear equations. $\mathrm{Jn}$ is a misrepresentation of the concept of a system of linear equations.

The next interview was summarized between $\mathrm{R}$ and Kt students. The subject gave an emphatic answer, but some errors occurred. The following is a snippet of the interview between $\mathrm{R}$ and $\mathrm{Kt}$.

$\mathrm{R}$ : Suppose there is a two-variable linear equation system $2 x-3 y+4=0 ;-x+y=1 \ldots$ How do you determine the solution?

Kt: I use the elimination method which means $\mathrm{y}=$ $\mathrm{x}+1$ and I remove $\mathrm{y}$ for $2 \mathrm{x}-3 \mathrm{y}+4=0$ to become $2 x+x+1+4=0$. ... that is $3 x+5=$ $0 \ldots 3 x=-5$ and $x=-5 / 3$.

$\mathrm{R}$ : Why did you finish like that?

$\mathrm{Kt}$ : Yes... I think that is the application of the elimination method.

R: ... how do you explain that $2 x-3 y+4=0$ becomes $2 \mathrm{x}+\mathrm{x}+1+4=0$ ?

$\mathrm{Kt}$ : Because $\mathrm{y}$ is eliminated by $\mathrm{x}+1 \ldots$

Based on the excerpt from the interview with $\mathrm{Kt}$, he incorrectly applies the principle of elimination, and misconceptions with substitution. However, $\mathrm{Kt}$ is also wrong in making the substitution, namely he is doing the substitution process of $\mathrm{y}=\mathrm{x}+1$ to the equation $2 x-3 y+4=0$ to $2 x+x+1+4=0$. This is a substitution error. Overall $\mathrm{Kt}$ also experienced errors in solving systems of linear equations through mixed methods.

Based on two snippets of interviews with Jn and $\mathrm{Kt}$, the students' mistakes in solving the linear equation system. These errors are misconceptions of linear equations, and misconceptions of systems of linear equations. Students also experience errors regarding the principle of solving systems of linear equations through elimination, substitution and mixed methods methods. These mistakes are misconceptions, principles and operations.

With these student mistakes, a mathematics learning approach is needed that can correct them. Because this is during the COVID-19 epidemic, students cannot possibly learn directly in class. It is a lesson that must be carried out online. Youtube also assisted [18], so that students can study in real time anywhere. In addition, to make it easier for students to carry out the process of abstraction, the process of achieving concepts and understanding principles, learning is carried out through the ethnomathematics approach. [16][19][20]. Therefore, in the following online and YouTube learning sessions:https://www.youtube.com/watch?v=R-

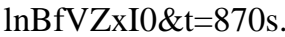

After the learning is complete, students are able to understand the concepts and principles of a system of linear equations with a good horizontal mathematical flow. Through Problem 1 about "pempek ikan" and "kemplang" which is described in Figure 1. Jn can provide the following settlement process.

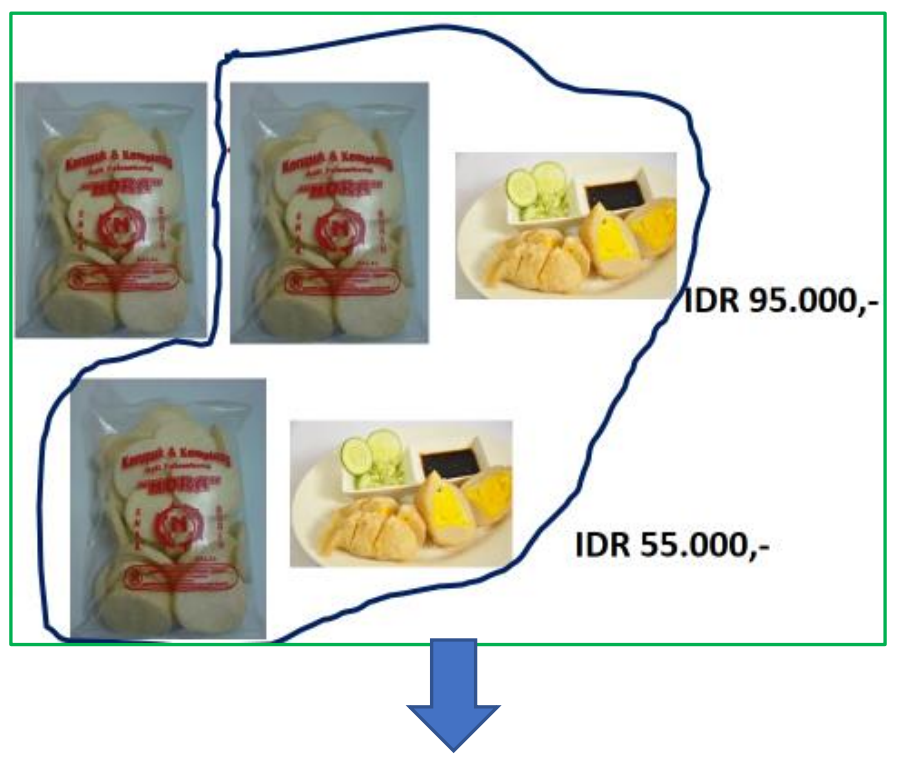




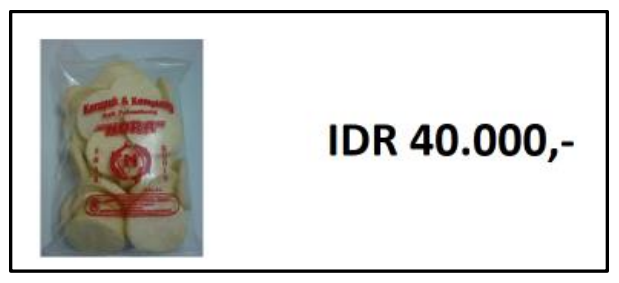

Figure 3. Solution through elimination

Based on Figure 3, it is the elimination process of a two-variable system of linear equations. It has been done by drawing as a system representation of linear equations. The first equation is two packs of "kemplang" and one plate of "pekmpek" at a price of 95,000 IDR. The second equation is a pack of "kemplang" and a plate of "pekmpek" for 55,000 IDR. Jn students have been able to eliminate one pack of "kemplang" and one "pekmpek" plate into one pack of "kemplang" at a price of 40,000 IDR. It is a horizontal mathematical process [21]. By finding a solution that the price of a pack of "kemplang" is 40,000 IDR, then Jn can substitute the equation for one pack of "kemplang" and one "pekmpek" plate for 55,000 IDR, so that the price of a "pekmpek" plate is 15.00 IDR. It can be seen in Figure 4.

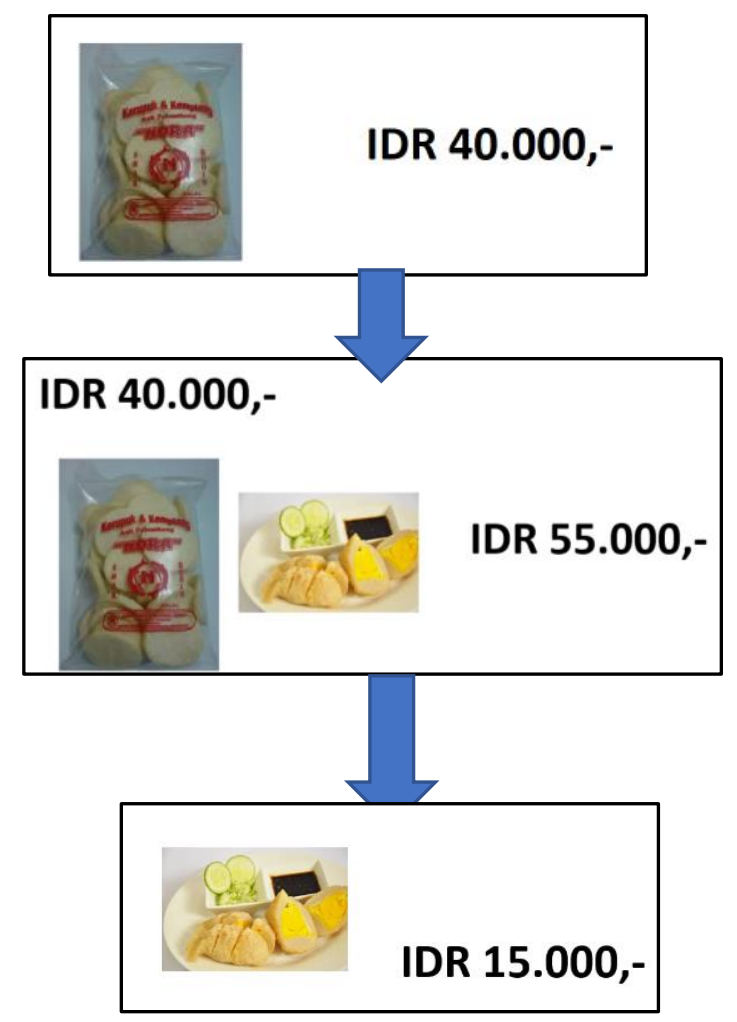

Figure 4. Solution by substitution

The mathematical process makes it easy for students to understand the concept of linear equation systems and also the principles of elimination, substitution and mixture. It is a local cultural approach, which has been able to improve the mathematics skills of junior high school students [19]. This means that the ethnomathematics approach assisted by realistic media can become a vehicle for students to simplify mathematical concepts to become more meaningful. [20].
Another student, $\mathrm{Kt}$, has also been able to understand systems of linear equations through local culture. Every Monday junior high school students always attend the flag ceremony. They wear a hat and tie in an orderly manner. When entering class, students are asked to group two ties and two hats for the first group. The second group is one hat and four ties. Both groups cost 30,000 IDR each. Without knowing the price for each hat and tie, can you determine which item is more expensive? Explain 
your reasons! b. How much is a hat? c. How much is a tie? d. How much for 2 hats and 5 ties? Through this local cultural approach, Kt has been able to solve these problems correctly. Consider Figure 5.

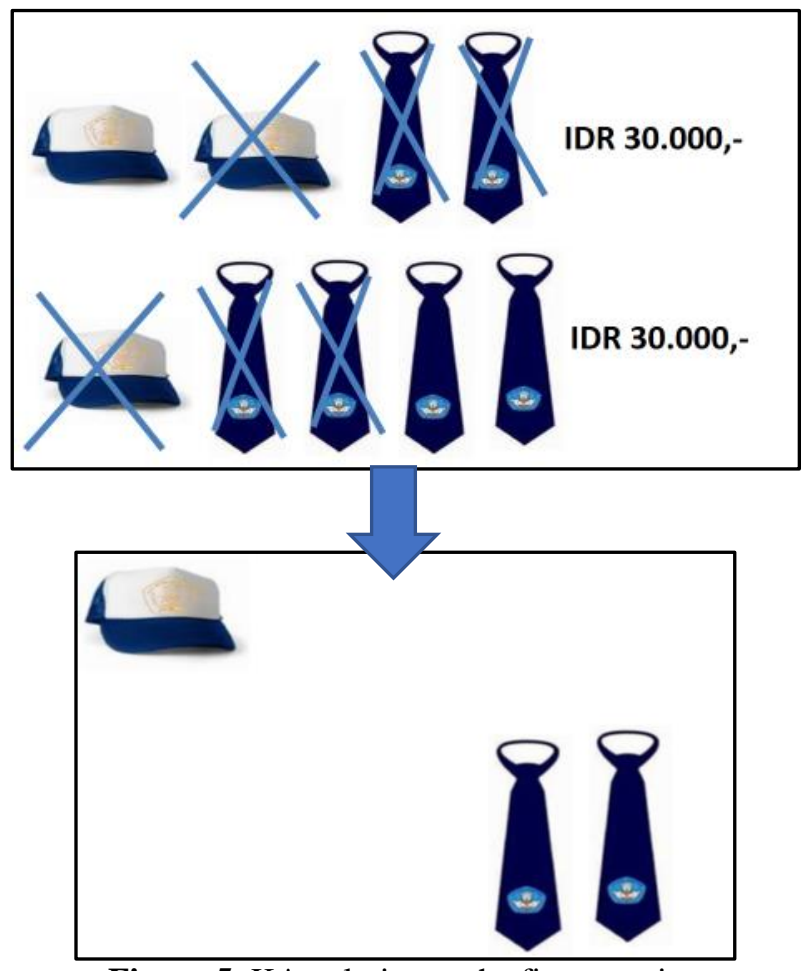

Figure 5. Kt's solution to the first question

Based on Figure 5, through culture using a hat and tie during the flag ceremony, without knowing the price of each hat and tie, the students were able to determine which item was more expensive. He stated that a hat was more expensive than a tie, because one hat cost the same as two ties. Through this local cultural approach, Kt has been able to solve these problems correctly. Consider Figure 5[11]. Furthermore, using the argument that the price of one hat is equal to two ties, Kt performs a cognitive process by replacing the two ties in the first equation (two hats and two ties costs 30,000 IDR) so that the thought process is obtained as shown in Figure 6.

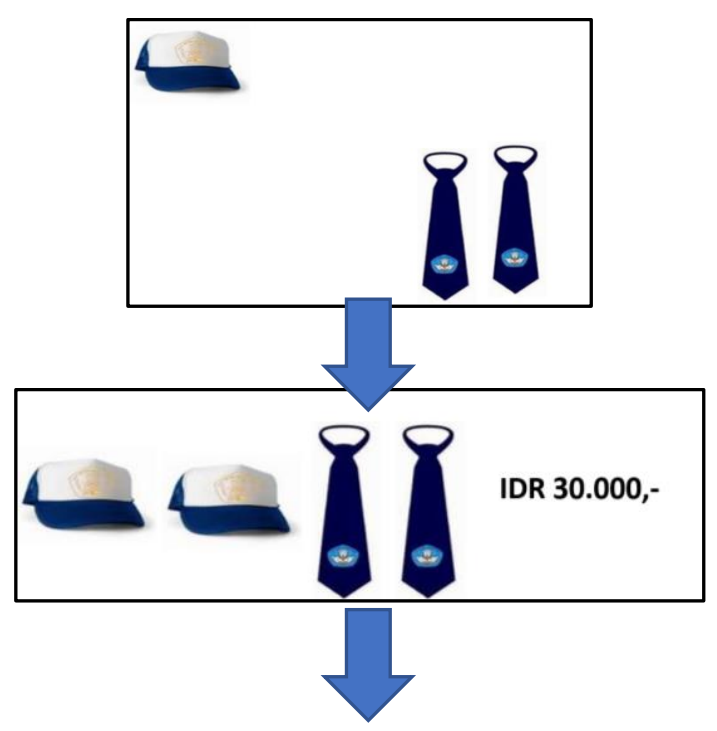




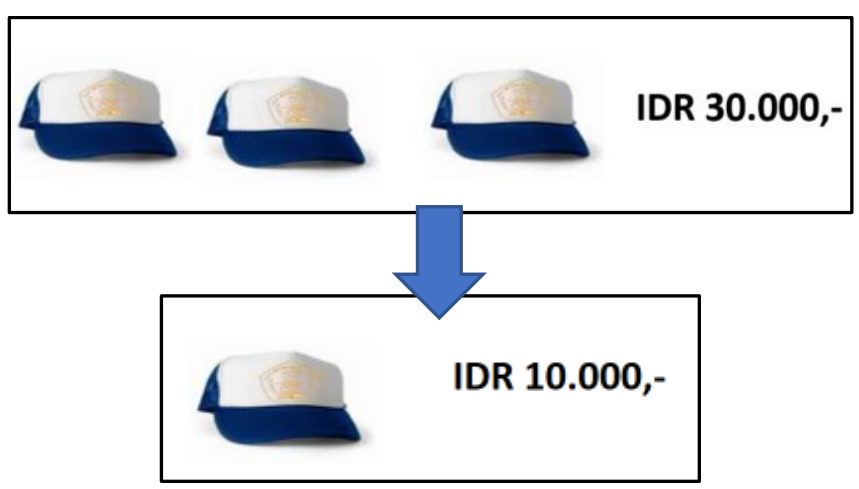

Figure 6. Substitution of two ties with a hat

Based on the $\mathrm{Kt}$ thought process as shown in Figure 6 , he is able to produce the equation of three caps for 30,000 IDR. Kt can easily get the solution that the price of one cap is 10,000 IDR. It has been done with the right process. Furthermore, by arguing that the price of one hat is equal to two ties, the second equation (the price of one hat and four of them is 30.00 - IDR) is to replace one hat with two ties. Consider Figure 7.

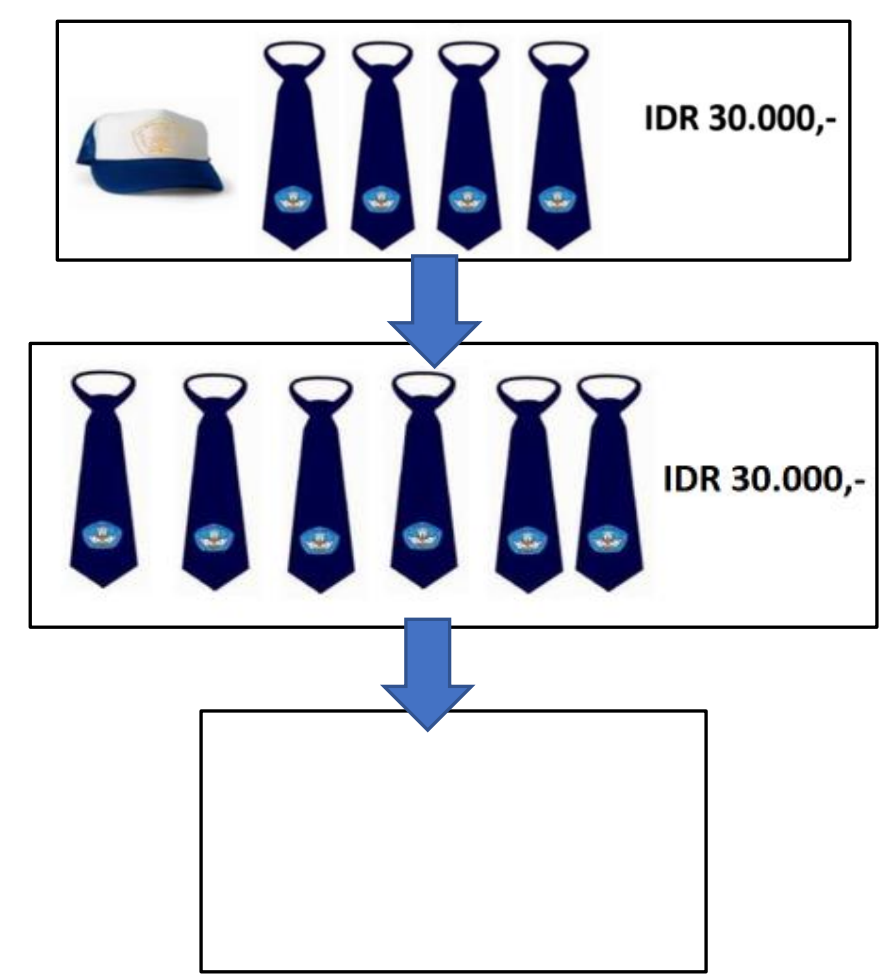

Figure 7. Solution of a system of equations through substitution

Based on Figure 7, students are able to obtain the equation that the price of six ties is $\mathrm{Kt}$ and have been able to solve the system of linear equations. He finished with the result that one tie costs 5000 IDR and one hat 10,000 IDR. Kt can then complete the next question, namely the price of two hats and five ties of 45,000 IDR (see Figure 8). 


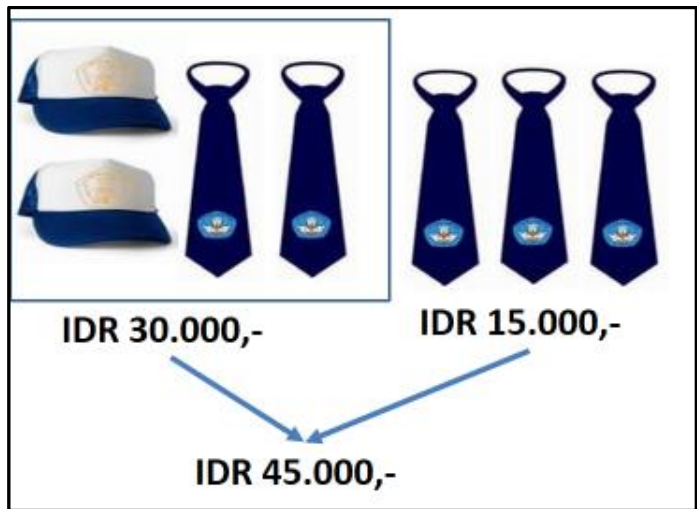

Figure 8. Solution to the third question

Based on the description of the results of this study, the technique of overcoming student errors during the COVID-19 pandemic is to apply an ethnomathematics approach taught through online learning. This has been implemented through the learning management system platform and assisted by the YouTube media. It supports many other studies, such as mathematics teachers being challenged to manage classrooms through the cultural diversity of society. Ethnomathematics has played a prominent and meaningful role in the exploration of various aspects of mathematical literacy [22]. The implementation of the ethnomathematics approach improves the students' contribution in linking formal and informal knowledge. These students are able to rediscover mathematical concepts and their perceptions of mathematics as a scientific discipline [23]. Also, the ethnomathematics approach assisted by YouTube media contributes to improving students' mathematical skills, especially problem solving [18], and understanding mathematical concepts [24]. Thus, we believe that mathematics learning suitable for junior high school students during the COVID-19 pandemic is a local cultural approach assisted by YouTube. It is able to overcome students' errors in understanding the concepts, principles and operations of the two-variable linear equation system for junior high school students.

\section{CONCLUSIONS}

The local cultural approach becomes the starting point for learning mathematics. Media YouTube presents mathematics learning content about systems of linear equations with local culture as an approach. Before learning through this approach students make mistakes in understanding the system of linear equations. These mistakes are misconceptions, principles and operations. After following mathematics learning through this approach, students' mistakes can be at the top well.

\section{REFERENCES}

[1] E. M. Mulenga and J. M. Marbán, "Prospective teachers' online learning mathematics activities in the age of COVID-19: A cluster analysis approach," Eurasia J. Math. Sci. Technol. Educ., vol. 16, no. 9, 2020.

[2] NCTM, "Moving Forward: Mathematics Learning in the Era of Covid-19 equitable access to high-quality mathematics teaching and learning," Natl. Counc. Teach. Math., no. June 2020, 2020.

[3] W. Widada, D. Herawaty, K. U. Z. Nugroho, and A. F. D. Anggoro, "The Scheme Characteristics for Students at the Level of Trans in Understanding Mathematics During Etno-Mathematics Learning," 3rd Asian Educ. Symp., vol. 8, no. Aes 2018, 2019.

[4] W. Widada, D. Herawaty, A. Falaq, D. Anggoro, A. Yudha, and M. K. Hayati, "Ethnomathematics and Outdoor Learning to Improve Problem Solving Ability," Adv. Soc. Sci. Educ. Humanit. Res. Vol. 295, vol. 295, no. ICETeP 2018, pp. 13-16, 2019.

[5] C. B. Yudha and D. A. Herzamzam, "Learning Mathematics In Pandemic Covid-19," JPD J. Pendidik. Dasar, vol. 1, no. 1, pp. 1-15, 2020.

[6] G. Di Pietro, F. Biagi, P. Costa, Z. Karpiński, and J. Mazza, The Likely Impact of COVID-19 on Education: Reflections based on the Existing Literature and Recent International Datasets, vol. EUR 30275, no. JRC121071. 2020.

[7] R. Kamsurya, "Learning Evaluation of Mathematics during the Pandemic Period COVID-19 in Jakarta," Int. J. Pedagog. Dev. Lifelong Learn., vol. 1, no. 2, p. ep2008, 2020.

[8] B. Ghirardini, E-learning methodologies: A 
guide for designing and developing e-learning courses. 2011.

[9] C. P. Cortez, "Blended, Distance, Electronic and Virtual-Learning for the New Normal of Mathematics Education: A Senior High School Student's Perception," Eur. J. Interact. Multimed. Educ., vol. 1, no. 1, p. e02001, 2020.

[10] Y. W. Lin, C. L. Tseng, and P. J. Chiang, "The effect of blended learning in mathematics course," Eurasia J. Math. Sci. Technol. Educ., vol. 13, no. 3, pp. 741-770, 2017.

[11] W. Widada, D. Herawaty, Y. Widiarti, S. Aisyah, and R. Tuzzahra, "The cognitive process of students in understanding the triangles in Geometry of Riemann through local content," Int. Semin. Appl. Math. Math. Educ. 2020 (2nd ISAMME 2020). J. Phys. Conf. Ser., vol. 1657 , no. 012033 , pp. $1-8,2020$.

[12] E. Zakaria and S. Mistima, "Analysis of Students ' Error in Learning of Quadratic Equations," Int. Educ. Stud., vol. 3, no. 3, pp. 105-110, 2010.

[13] W. Widada, D. Herawaty, D. Yanti, and D. Izzawati, "The Student Mathematical Communication Ability in Learning Etnomathematics Orieted Realistic Mathematics," Int. J. Sci. Res., vol. 7, no. 9, pp. 881-884, 2018.

[14] W. Widada, D. Herawaty, M. H. Rahman, D. Yustika, and P. Elsa, "Overcoming the difficulty of understanding systems of linear equations through learning ethnomathematics," IOP Conf. Ser. J. Phys. Conf. Ser. 1470012074 doilo.1088/1742-6596/1470/1/012074, vol. 1470, pp. 1-14, 2020.

[15] W. Widada, S. Efendi, D. Herawaty, and K. U. Z. Nugroho, "The genetic decomposition of students about infinite series through the ethnomathematics of Bengkulu, Indonesia," IOP Conf. Ser. J. Phys. Conf. Ser. 1470012078 doilo.1088/1742-6596/1470/1/012078, vol. 1470, pp. 1-9, 2020.

[16] D. Herawaty, W. Widada, H. Ardy, R. Furqany, and A. F. D. Anggoro, "The abstraction ability about natural numbers through playing traditional music for elementary students," Int. Semin. Appl. Math. Math. Educ. 2020 (2nd
ISAMME 2020). J. Phys. Conf. Ser., vol. 1657, no. 012039, pp. 1-6, 2020.

[17] W. Widada et al., "How are the process of abstraction of the division of fraction numbers by elementary school students?," Int. Semin. Appl. Math. Math. Educ. 2020 (2nd ISAMME 2020). J. Phys. Conf. Ser., vol. 1657, no. 012040, pp. 1-7, 2020.

[18] K. U. Z. Nugroho, W. Widada, and D. Herawaty, "The Ability To Solve Mathematical Problems Through Youtube Based Ethnomathematics Learning," Int. J. Sci. Technol. Res., vol. 8, no. 10, pp. 1232-1237, 2019.

[19] W. Widada, D. Herawaty, D. S. Andriyani, R. Marantika, and I. D. Yanti, "The thinking process of students in understanding the concept of graphs during ethnomathematics learning," IOP Conf. Ser. J. Phys. Conf. Ser. $1470 \quad 012072 \quad$ doilo.1088/1742. 6596/1470/1/012072, vol. 1470, pp. 1-8, 2020.

[20] D. Herawaty, W. Widada, A. Adhitya, R. D. W. Sari, and L. Novianita, "Students' ability to simplify the concept of function through realistic mathematics learning with the ethnomathematics approach," IOP Conf. Ser. J. Phys. Conf. Ser. 1470012031 doilo.1088/17426596/1470/1/012031, vol. 1470, pp. 1-8, 2020.

[21] A. Fauzan, "Applying Realistic Mathematics Education (RME) In Teaching Geometry In Indonesian Primary Schools," University of Twente, 2002.

[22] K. François, "The Role of Ethnomathematics Within Mathematics Education," Proc. Cerme, pp. 1517-1526, 2010.

[23] C. Stathopoulou, P. Kotarinou, and P. Appelbaum, "Ethnomathematical research and drama in education techniques: developing a dialogue in a geometry class of 10th grade students," Rev. Latinoam. Etnomatemática, vol. 8, no. 2, pp. 105-135, 2015.

[24] D. Andriani et al., "Understanding the number concepts through learning Connected Mathematics (CM): A local cultural approach," Univers. J. Educ. Res., vol. 8, no. 3, pp. 10551061, 2020. 